\title{
LAURA BENITEZ
}

\section{J. M. Gallegos Rocafull y la cultura}

La gran obra de la vida como de la sociedad y de la historia es contribuir a que se realicen todas esas posibilidades que hay en el fondo íntimo de cada persona y ayudarle eficazmente a que cumpla con su destino.'

\section{1.l Introducción}

- $\mathrm{N}$ el año 1963 , pocos meses antes de su muerte, conocí a Gallegos Rocafull, quien fue mi profesor de filosofía de la historia durante un semestre. Su fallecimiento fue la causa no sólo de aquel curso inconcluso sino también de mi necesidad de indagar las preferencias filosóficas de mi maestro. A través de sus clases logré enterarme de algunas de sus preocupaciones, sin embargo, al recorrer por mi cuenta su obra escrita, he encontrado un pensamiento bien delineado y maduro cuyas aportaciones más relevantes se dieron en el ámbito de lo que hoy llamamos filosofia de las ciencias sociales.

Entre los temas filosóficos, que más interesaron a GR, destacan: el relativo al valor de la persona; la importancia de la vida social; la explicación e interpretación de la historia; la historia del pensamiento mexicano, etc.

Debido a la diversidad de los temas he decidido ceñirme al de la cultura, a la que considero una categoría fundamental en el pensamiento de GR, quien la desarrolló, directa o indirectamente, en varios ensayos y pequeños tratados:

1 Gallegos Rocafull, J.M. Personas y masas, México, Ed. Valle, 1974, p. 23. 


\subsection{La cultura como "el tema de nuestro tiempo"}

Preocupado, como muchos otros autores, por el destino de la cultura occidental, en la década de los años cuarenta GR escribió diversos ensayos y artículos sobre este problema.

La cultura es el producto de la actividad humana en todos los niveles: "Donde quiera que hay hombres hay una cultura y viceversa, el hecho de que exista una cultura prueba que son hombres los que la crean y viven."

Si se busca una idea más específica y clara de lo que es la cultura para GR, habrá que remitirse a Personas y masas, donde dice:

... una cultura [es]... un sistema de creencias y soluciones, a base del cual organizan los hombres su vida y construyen un determinado tipo humano, vigente hasta el momento en que, si la sociedad no ha de morir, siente la comezón de internarse en las regiones desconocidas que le circundan y cosechar en ellas nuevas empresas que determinen su futuro inmediato. ${ }^{3}$

Por lo pronto la cultura es una empresa humana dinámica; sin embargo, lo que interesa es determinar las causas de su deterioro. ¿Por qué el malestar, por qué las denuncias de crisis cultural?

Al examinar las causas posibles de la crisis GR distingue tres aspectos que son otras tantas características de la cultura occidental: su contenido, su unidad y su organización. De este examen concluye que si el contenido de la cultura es histórico y dinámico, cambiante y renovable, ello es una nota de vigor y salud y no de enfermedad o caducidad. En cuanto a la unidad, le parece que la cultura occidental presenta una unidad de herencia en el pasado común que sirve de marco de referencia a vastas comunidades humanas. Además presenta una unidad de vida, por la forma en que se ha extendido, y de destino, que es el de salvar, construir o realizar al hombre occidental.

2 J.M. Gallegos Rocafull, "El maestro Francisco de Vitoria como forjador de cultura" en Filosofía y Letras, núm. 22, abril-junio 1946, México, Imprenta Universitaria, p. 216.

3 J.M. Gallegos Rocafull, Personas y masas, p. 194. 
En cuanto a la organización, en cada época de la cultura occidental ha habido una idea rectora que puede provenir de cualquier sector: el religioso, el político o el económico; y a partir de dicha idea se estructura todo el sistema.

Es este último aspecto en el que podría encontrarse la causa de la crisis, no obstante, GR duda. En su ensayo sobre "La crisis de Occidente", sugiere que no hay en la actualidad una idea rectora de la cultura y señala este hecho como una de las posibles causas de la crisis, pero en Personas y masas, considera que hay una idea rectora en nuestra cultura actual que proviene del sector económiço.

El diagnóstico general que se obtiene de la lectura de los textos de GR es que la crisis de la cultura no proviene de ella misma sino de quienes la producen y viven, esto es, de los hombres o mejor aún, del proceso en que los hombres devienen, ya personas, ya masas.

\subsection{Personas y sociedad}

Para entender la complejidad de la crisis actual de la cultura GR toma como punto de referencia a la persona, pues:

... todo cuanto acaece en el orden de la existencia, como en el del conocimiento, si realmente es importante, está íntimamente relacionado con las personas a las que en definitiva siempre las está haciendo o deshaciendo. ${ }^{4}$

El ser humano para constituirse como persona necesita realizar un esfuerzo propio; no obstante, en todas las etapas de constitución que GR señala, destaca la auténtica dimensión del ámbito social.

En una primera etapa todo individuo toma la cultura dada, cristalizada, de su entorno social. Posteriormente, la persona que lleva la impronta del grupo, se separa de él por su propia fuerza creadora. Finalmente, si logra consolidarse como persona, esto es, si logra encontrar la vía de su personal misión, podrá ver el mundo y vivir la vida con su propio criterio, a la

${ }^{4}$ Op. cit., p. 11. 
vez que repercutirá en la sociedad enriqueciéndola, por su singular manera de ser persona.

Las personas son seres humanos vitales que, canalizando sus energías, se superan a sí mismos. Lo importante no es cobijar en grupo las mutuas debilidades, sino superarlas, sublimando las limitaciones y esa labor sólo puede ser individual. Por otro lado, las personas son aquellos individuos conscientes de que tienen una misión; por lo que buscan realizar sus propias posibilidades y se responzabilizan de su programa de vida.

Paralelamente a las tesis que señalan el papel del individuo en su constitución como persona, GR expone el papel que en ello desempeña la sociedad.

El hombre, en efecto, no llegaría a ser tan persona sin la resonancia que le da el mundo social. No es en la soledad sino en la comunión con los demás seres donde los hombres se afirman como personas, obtienen una función, desempeñan su misión y dan a su vida la amplitud y profundidad que caracteriza a la persona. ${ }^{5}$

Esta misión básica de la vida individual humana que consiste en hacerse persona, implica para GR la posibilidad de dar cuerpo, de hacer presentes y vivos los valores del espíritu, pues aunque los valores están dados en las diversas instituciones sociales de donde cada uno los toma, en el camino de hacerse persona lo interesante es vivificarlos, renovarlos y servir de puente entre el mundo de los valores y la comunidad.

Naturalmente, no todos los hombres tienen la misma misión histórica, porque no todos luchan en igual forma para vencer su propia finitud, pero:

La más sumaria explicación de la creación cultural, tendrá que contar de algún modo con estos elementos, $\mathrm{y}$ ha de ver en ella, armoniosamente fundidos, la singular aptitud o inspiración de un individuo determinado y las fuerzas oscuras que emanan del pueblo, determinándole y sosteniéndole en su obra creadora. ${ }^{6}$

5 lbid., p. 15.

6 J.M. Gallegos Rocafull, "El maestro Francisco...", p. 206. 
Hasta ahora sólo se ha hablado de la constitución del hombre en persona; pero si este proceso siempre se efectuara la cultura no se vería nunca en problemas. El ideal es pues, una sociedad cuyos integrantes sean auténticas personas. No obstante, existen en todos los sistemas sociopolíticos actuales factores que propician la despersonalización. Ello se puede observar, según GR, tanto en el totalitarismo como en la democracia o el comunismo. El problema reside en que se trata de sobreponer lo social a lo individual. Un factor de socialización negativa que anonada a la persona.

... la sociedad lejos de empequeñecer y dañar a los individuos, es el medio obligado en que se han de desenvolver; ni hay individuos sin sociedad, ni sociedad sin individuos, aunque el mismo análisis lleve e imponga una prevalencia de lo personal sobre lo social; cuando de hecho es así, las relaciones son normales y no hay problemas, pero si se invierte la prelacía se rompe la normalidad y como de un avispero sale todo un enjambre de problemas. ${ }^{7}$

El problema básico del que GR ha hecho un análisis cuidadoso es el de la formación de hombres-masa. Una vez invertida la relación sociedad individuo, la sociedad actúa aplastando la personalidad del hombre, tornándole uno más en la serie de todos aquellos que constituyen un tipo común.

No es que el hombre-masa sea malvado o estrictamente limitado, se trata simplemente de un individuo: "perfectamente sustituible por cualquier otro", que no posee una personalidad propia, que al no elaborar su programa de vida no puede servir de enlace entre los valores, de los que carece, y su comunidad. No hay en el hombre-masa una conciencia o responsabilidad de su propia existencia. El hombre-masa es síntoma de la crisis cultural actual.

...lo que no sucedió, hasta que el hombre-masa hizo su aparición es que la función social que se desempeña o el grupo a que se pertenezca, absorban de tal modo toda la persona que ésta

7 J.M. Gallegos Rocafull, Personas y masas, p. 173. 
deje de serlo para siempre, hasta en sus reconditeces más íntimas, para convertirse en miembro de la sociedad y nada más. ${ }^{*}$

\subsection{Personas y cultura}

En vista de que el carácter social humano, o más precisamente, la convivencią humana tiene como tarea fundamental lograr el desenvolvimiento de cada uno de sus miembros en persona, es importante señalar que, para GR, dicha meta sólo puede alcanzarse a través de los bienes culturales. Dichos bienes constituyen no sólo el aspecto fundamental del ámbito social por su carácter formativo sino por la peculiaridad que tienen de acrecentarse a través del uso.

La obra de acrecentamiento cultural se funda en el dinamismo del grupo humano. “...ningún grupo se agota en la obra que está realizando en cualquier instante de su historia sino que siempre su obra actual está preparando la futura."

En efecto, la sociedad compuesta por diversos grupos se revitaliza en la producción cultural. Para GR los grupos de intelectuales, artistas, hombres religiosos, etc., han tenido históricamente su "momento" y ello se ha concretado en una guía por parte del grupo dirigente de la producción cultural en general. Este dinamismo y equilibrio de grupos explica la riqueza de la cultura y condiciona el desarrollo de los individuos como personas.

Naturalmente los grupos cristalizan en instituciones: iglesia, Estado, economía, etc.; pero lo importante es conservar el equilibrio entre ellos, ya que el verdadero orden social se funda en la posibilidad de "Defender la independencia y libertad de cada una de estas instituciones en su ámbito propio y buscar la coordinación de todas ellas a fin de desarrollar y enriquecer a la persona humana." 10

En el ámbito de la creación y transmisión de la cultura $\mathrm{GR}$ adopta una interesante tesis axiológica. Lo primero es que

\footnotetext{
${ }^{8}$ Op. cit., p. 26.

${ }^{9}$ Ibid, p. 176.

${ }^{10}$ lbid., p. 180.
} 
reconoce, como existentes, bienes culturales con características peculiares.

Los bienes culturales son:

...universales en el doble sentido de que pretenden validez universal y están a todos patentes - la religión, la ciencia, el derecho- son por ello eminentemente sociales y, a la vez, los más personales, puesto que únicamente las personas los crean, los gozan y los transmiten. ${ }^{11}$

Los valores de los que habla GR son perennes y expresan lo auténticamente humano del hombre. Sin embargo, la única cultura capaz de semejante universalidad y perennidad es la cultura occidental.

Para GR la cultura occidental posee un àrsenal de valores semper válidos que se han concretado en el humanismo clásico y en el cristianismo. Cabe preguntarse ¿cómo se hacen presentes a los individuos de una sociedad tales valores?

Dentro de la línea idealista que se va descubriendo en el pensamiento de GR, aparece el concepto de Weltanshaung (concepción del mundo) como crisol de los valores de una cultura.

Por encima o por debajo de los valores que realiza una cultura, a parece siempre esta especie de emanación, del alma colectiva o espíritu objetivado, que se manifiesta por igual en sus dominios más diversos y da, a cada cultura su acento peculiar, ese matiz característico que hace que sea lo que es y no se confunda con ninguna otra. ${ }^{12}$

La concepción del mundo es para GR serie de creencias que los individuos de una sociedad han tomado de manera espontánea y natural como fundamento para el desarrollo de sus existencias personales. Anterior a la formación de cualquier ámbito cultural, "La raíz última de toda cultura, dice GR, es esa concepción del hombre y del mundo, completamente despersonalizada, fundamentada no en pruebas sino en pura

$"$ Ibid., p. 48.

12 J.M. Gallegos Rocafull, "El maestro Francisco...", p. 201. 
fe, que siendo de todos y por serlo no es de nadie, en la que se vive, no por aceptación reflexiva, sino por herencia y por contagio." 13

La cultura no sólo está determinada por circunstancias externas sino por este elemento más sutil, la concepción del mundo, mediante la cual los hombres de una sociedad se orientan hacia unos valores y desechan otros. Se suscitan así, problemas inaplazables a los cuales se da respuesta con creaciones culturales concretas guiadas por los valores que emanan de una determinada concepción del mundo.

Uno de los factores determinantes en la actual crisis cultural es que no existe una concepción del mundo vigente y unificada.

No es que no haya una o hasta varias concepciones del mundo; las hay y para todos los gustos, pero ninguna tiene plena vigencia social; son creencias de individuos o de grupos relativamente reducidos, que no logran el asentimiento unánime o, al menos, de la mayoría de los hombres que viven la cultura occidental, ni pueden, por lo tanto, ser como el sustrato firme y último en que se apoyen sus costumbres, ideas e instituciones. ${ }^{14}$

Al no ser producto de un ejercicio racional la concepción del mundo no puede ser sustituida con ninguna otra forma procedente de la razón. De ahí la profundidad de la crisis cultural para GR quien supone que:

1. Toda cultura debe apoyarse en una concepción del mundo como conjetura amplia y general.

2. Dicha concepción del mundo da lugar al desarrollo específico de los valores.

3. A partir de la clarificación de los valores se desarrollan los distintos ámbitos culturales.

4. La misión de una sociedad es dotar de estos elementos a los individuos quienes los harán propios para poder convertirse en personas.

${ }^{13}$ Op. cit., p. 201.

14 J.M. Gallegos Rocafull, "La crisis de occidente" en Filosofia y' Letras, núm. 34, abril-junio, 1949, México, Imprenta Universitaria, p. 207. 
5. Cuando el individuo ha asimilado y acrecentado los valores su misión es trascenderse a sí mismo al vincular el mundo de los valores a su comunidad.

6. La cristalización de los valores es empresa individual por el impulso de la persona, pero también comunitaria, por cuanto el grupo empuja hacia su realización.

7. Los grupos humanos entran en relaciones de equilibrio o armonía cuando se impone un grupo con un valor determinante que se patentiza en alguna institución rectora. Sin embargo, es indispensable el libre juego de los grupos humanos para el sano desarrollo de la cultura.

8. Por todo lo anterior, si se carece de la base, Weltanshaung, la cultura se hunde. Así, ¿cuál puede ser la salvación para nuestra cultura occidental actual?

\subsection{Nuevo tipo de hombre y nueva cultura}

La cultura es vital para el ser humano como primer resultado de la convivencia, pues constituye el camino de su realización, a la vez que cada región cultural posibilita el desarrollo de las diversas facultades de cada ser humano, y eso le permite a éste irse constituyendo, como persona que es, justamente su salvación.

Para Gallegos la cultura en su conjunto es medio de salvación del hombre, sin embargo, hay maneras muy diversas de vivir, de realizarse, de constituirse, de ser hombre, puesto que cada uno está lleno de posibilidades y sobre todo de una fuerza creadora que le permite hacerse a sí mismo.

No puede uno dejar de reconocer el origen fuertemente existencial de la propuesta, pero además tiene un tono optimista que le viene de su visión humanista clásica y cristiana.

Dentro de cada cultura se producen soluciones vitales que van constituyendo un tipo de hombre, una manera específica de ser persona dentro de la enorme variedad de posibilidades de serlo. El tipo de hombres que genera una cultura, “... no son más que las variaciones posibles dentro del marco más o menos amplio de un mismo género de vida espiritual." 15

15 J.M. Gallegos Rocafull, “El maestro Francisco...” p. 215. 
No se entiende, por tipo, una forma estandarizada de ser que representa la situación del hombre-masa, sino una manera personal de enfrentar los problemas con el sello más básico de una serie de valores compartidos que se sostienen en profundas creencias comunes. Es en este sentido, en el que las energías o potencialidades del hombre se ven condicionadas por la sociedad, y por ello puede afirmarse que el tipo de hombre variará según varíe la sociedad.

En la base de esta afirmación está la concepción antropológica que hace del hombre, no una cosa rígida, inmutable, perenemente igual a sí misma, sino un ser fluidizo y cambiante, todo él posibilidad, o mejor panorama de posibilidades, cada una de las cuales se realiza realizándose él según quiera y pueda. ${ }^{16}$.

Si la cultura actual está en crisis es porque el hombre carece de una fe básica integral que proporcione algún credo político o filosófico. Carece de una visión del mundo prerracional que, en un sentido general, pueda llamarse fe religiosa. $\mathrm{La}$ fe integral permite al hombre encontrar el sentido y el valor de su ser, su para qué en el mundo, esto es, su misión peculiar.

Estará vencida la crisis cuando el hombre recobre esta fe humana en su misión, en su destino, en su porvenir, que es el aliento de toda su obra creadora. ${ }^{17}$

Sin embargo, el nuevo tipo de hombre no surge espontáneamente, responde a una nueva cultura que para GR se concreta en el desarrollo y universalización de la cultura occidental y sus valores más sobresalientes, y que denomina nuevo humanismo o humanismo integral.

Por desarrollo de la cultura occidental debe entenderse que sus principios o valores básicos, a saber, los del humanismo clásico y los del humanismo cristiano son esencialmente permanentes pero susceptibles de diversos desarrollos, por lo que sirven de base a múltiples culturas o soluciones diversas.

16 J.M. Gallegos Rocafull, Personas y masas, p. 20.

17 J.M. Gallegos Rocafull, "La crisis de occidente...", p. 218. 
El humanismo integral debe realizar al hombre en todas sus dimensiones, para lo cual se requiere reconocer que el principal y más importante atributo del ser humano es su condición humana. Esto constituye la parte medular del nuevo humanismo. No se trata pues sino de entender que la vida, la libertad y la misión del hombre son partes fundamentales de su ser.

El hombre tiene que desenvolverse libremente porque ha de realizar una misión. La misión, la convicción íntima de que se está en el mundo para cumplirla, es, más que trabajo, responsabilidad. ${ }^{18}$

La responsabilidad, es saber no sólo cuáles son los alcances y límites, lo que se puede, sino más bien saber qué es lo que se debe hacer. Se trata de la responsabilidad moral para consigo mismo y para con los demás. Esta misión sólo puede cumplirse en la producción de la cultura, ahí donde cada ser humano se hace persona, donde se rebasa el mundo natural para entrar plenamente en la esfera de lo humano y, más aún para GR, de lo espiritual.

Por eso el nuevo humanismo a la trilogía, vida, libertad y misión, propia del hombre, tendrá que añadir la díada, trascendencia e intimidad, características de la persona.$^{19}$

Para el desarrollo de sí mismo el hombre debe volverse a la interioridad sin divertirse en un esfuerzo por alcanzar los bienes del espíritu, y muy específicamente, el supremo bien espiritual, Dios.

\subsection{Deificar, la misión del intelectual}

Dentro de las diversas maneras de ser hombre la misión del intelectual se considera como la guía de la comunidad. Particularmente la misión del filósofo consiste en esclarecer y mejorar a sus semejantes. "Nada de la odiosa y repugnante torre de

${ }_{18}$ Op. cit., p. 217.

19 Ibid., p. 218. 
marfil, dice GR, el retiro del filósofo dista mucho de ser refinado egoísmo; es o ha de ser, tumultuosa o dolorosa germinación de ideas y de principios que orienten a los demás."20

El hombre que conquista su libertad interior en la cual reside su máxima fortaleza, debe enseñar a los demás a conquistarse a sí mismos, a ser auténticas personas libres. Es el intelectual quien debe suscitar y ayudar a cumplir en todos los hombres esta legítima aspiración, su peculiar deificación. Finalmente GR nos advierte:

Falla la ciencia y en general la cultura, cuando en vez de servir al hombre le esclaviza, porque en lugar de penetrar hondamente en su espíritu y ser como los cauces naturales de su actividad vital, se queda en la superficie y forma en ella, una costra seca y sucia, bajo la cual pugne inútilmente là vida por abrirse paso. ${ }^{21}$

Otoño de 1985

20 J.M. Gallegos Rocafull, Prólogo a las Cartas morales de Séneca, México, UNAM, 1945, p. 20.

${ }^{21}$ J.M. Gallegos Rocafull, "Ideas del Fausto para la filosofia de la historia", en Filosofia y Letras, núm. 35, julio-septiembre, 1949, México, Imprenta Universitaria, p. 41. 